\title{
La fundación del Cuzco incaico a través de las crónicas coloniales: un estudio a partir de Juan de Betanzos (1551) y Juan de Santa Cruz Pachacuti (1613)
}

\author{
Fabián Andrés Topres Chacón \\ Universidad Estadual de Campinas (Unicamp), Campinas-SP, Brasil \\ ftorreschacon@gmail.com
}

\section{RESUMEN}

El siguiente trabajo tiene por objetivo

serán útiles los conceptos teóricos de estudiar los mitos fundacionales del Cuzco incaico en la documentación colonial de los siglos siglo XVI y XVII. Se tomarán como fuentes principales las obras de Juan de Betanzos (1551) y Juan de Santa Cruz Pachacuti (1613). Con el objetivo de abordar los supuestos relatos orales a los que tuvieron acceso los cronistas que se enmarcaban dentro de la memoria andina, memoria y memoria cultural. Además, se dará importancia a los principales actores que participaron dentro de la fundación del Cuzco, como: Manco Cápac, Mama Huaco, los hermanos Ayar y las divinidades de Viracocha y Tonapa.

Palabras clave: crónicas; escritura; memoria; oralidad.

Cómo citar: Torres Chacón, F. (2019). La fundación del Cuzco incaico a través de las crónicas coloniales: un estudio a partir de Juan de Betanzos (1551) y Juan de Santa Cruz Pachacuti (1613). Ciencias Sociales y Educación, 8(16), 23-41. DOI: https://doi.org/10.22395/csye.v8n16a2

Recibido: 27 de julio de 2019.

Aprobado: 25 de septiembre de 2019. 


\section{The Cuzco Incaico Foundation Trough the Colonial Cronicle: an Estudy from Juan de Betanzos (1551) and Juan de Santa Cruz Pachacuti (1613)}

\section{ABSTRACT}

This work has the main purpose of studying the foundational myths of the Inca Cusco in the colonial documentation from the XVI and XVII centuries. The works by Juan de Betanzos (1551) and Juan de Santa Cruz Pachacuti (1613) will be the main sources. With the purpose of tackling the alleged oral stories, they had access to, which are framed in the Andean memoirs, the concepts of memory and cultural memory. Furthermore, a high relevance will be given to main actors in the foundation of Cusco: Manco Cápac, Mama Huaco, the Ayar brothers and the Viracocha and Tonapa divinities.

Keywords: chronics; writing; memory; orality.

\section{A fundação do Cuzco incaico por meio das crônicas coloniais: um estudo com base em Juan de Betanzos (1551) e em Juan de Santa Cruz Pachacuti (1613)}

\section{RESUMO}

Este trabalho tem o objetivo de estudar os mitos da fundação do Cuzco incaico na documentação colonial dos séculos XVI e XVII. São utilizadas como fontes principais as obras de Juan de Betanzos (1551) e de Juan de Santa Cruz Pachacuti (1613). A fim de abordar os supostos relatos orais aos quais os cronistas tiveram acesso, que se enquadravam na memória, são úteis os conceitos teóricos de memória e memória cultural. Além disso, é dada importância aos atores principais que participaram da fundação do Cuzco, como: Manco Cápac, Mama Huaco, os irmãos Ayar e as divindades de Viracocha e Tonapa.

Palavras-chave: crônicas; escrita; memória; oralidade. 


\section{Introducción}

Los documentos coloniales de los siglos XVI y XVII del Virreinato del Perú, se han convertido en fuentes de referencia para el estudio del pasado colonial —en algún caso prehispánico- de los Andes centrales. El estudio y análisis de dichas fuentes ha motivado preguntas y problemas de investigación sobre algunos temas, que si bien cuentan con la producción de una literatura crítica, despiertan en los investigadores del pasado andino y el Perú antiguo un alto grado de interés y atención. Entre estos temas podríamos mencionar la representación y descripción de los sistemas religiosos, así como del tiempo y el espacio andino, entre otros.

Para la ocasión de este artículo, el foco de análisis estará dirigido hacia los diferentes mitos fundacionales del Cuzco incaico, lugar donde se daría origen a la expansión y dominación del grupo inca en el territorio andino. Se tomarán como fuentes principales dos manuscritos realizados entre los siglos XVI y XVII; la Suma y narración de los incas (1551) de Juan diez de Betanzos y la Relación de antigüedades deste reyno del Piru (1613) de Juan de Santa Cruz Pachacuti.

Desde el punto de vista teórico y metodológico, se analizará el contexto histórico y político en el que los autores redactaron sus obras, así como su posición e inserción dentro de la sociedad colonial, sus aspiraciones y motivaciones para elaborar sus escritos. Asimismo, se considerará a pedido de quién y para quién iban dirigidos. Otro aspecto que tendrá que ser valorado — quizá uno de los más importantes - es el nivel de acceso y conocimiento de los cronistas sobre la sociedad indígena, su lengua, relatos y sistemas religiosos, etc.

Por último, abordaremos teóricamente el concepto de memoria para ver si puede ser visto y analizado como algo que conserve los diferentes relatos indígenas sobre la fundación del Cuzco y cómo estos relatos inscritos en un tipo de memoria fueron transmitidos a los cronistas y, por ende, llevados a la escritura alfabética de la época colonial.

\section{Suma y narración de los incas de Juan de Betanzos}

Juan de Betanzos fue el autor de la Suma y narración de los incas escrita alrededor de 1551. Para la historiadora María del Carmen Martín Rubio, la vida de Betanzos es oscura y novelesca, sobre todo antes de asentarse como vecino en Cuzco' ${ }^{1}$.

\footnotetext{
"Juan de Betanzos es el autor de la Suma y narración de los incas, una de las primeras obras de carácter indigenista, escrito según él mismo expone en Cuzco, la capital sagrada de los incas, por los años de 1551. Su vida es oscura y novelesca, sobre todo antes de afincarse como vecino en el cuzco. Fundándose en su apellido, se le ha considerado nacido en Galicia, por indicación del historiador y literato gallego Manuel Martínez Murguía. Yo pongo en duda este origen y pienso que, muy posiblemente, vio la luz de sus días en Valladolid. Me baso para hacer tal afirmación en dos cartas existentes en la colección de documentos inéditos del Archivo General de Indias de Sevilla. En una de ellas se hace referencia a Juan de Betanzos y la otra está escrita por el mismo" (Martín Rubio, 1987, p. XI).
} 
Esta autora propone como lugar de nacimiento para el cronista la ciudad de Valladolid. Cómo y cuando llegó Juan de Betanzos al Cuzco sigue siendo un gran enigma, pues se cuenta solo con la escasa información que él mismo dejó en su crónica. A pesar de esto, autoras como Lidya Fossa (2006) proponen como fecha de llegada de Betanzos al Perú los años de 1534 o 1535. Por otra parte, uno de los primeros editores de la obra de Betanzos, Jiménez de la Espada (1880), dice que el cronista llegaría al Perú junto con la campaña militar de Francisco Pizarro, y con el tiempo se volvería un conocedor y estudioso del idioma quechua. Esto lo llevaría a ocupar altos cargos en la administración colonial y a tener una estrecha relación con la élite incaica, debido también a su matrimonio con una ñusta o princesa inca.

El matrimonio de Betanzos con la ñusta inca Cuxirimay Ocllo no debe ser considerado un hecho menor, pues su acomodada posición dentro de la administración colonial y élite incaica, le darían las condiciones para ser un gran estudioso y conocedor de la cultura indígena:

Su unión con la princesa inca, indudablemente, le proporcionó un gran prestigio entre los nobles y parientes de su mujer, y sobre todo le llevó a adquirir una fuente de holgura económica, como demuestra el doctor Villanueva Urteaga en el magnífico trabajo insertado en la presente edición, por eso tal vez abandonó el oficio de escribano, con el que tan mal le había ido en Santo Domingo y se dedicó a fomentar sus estudios del quechua, convirtiéndose en el intérprete o lengua ideal del gobierno hispano, recién instaurado en el cono sur de América, y enseguida denominado virreinato peruano. (Martín Rubio, 1987, p. XVI)

Pero ahí no terminan los particulares privilegios de los cuales gozó Betanzos. En un pequeño artículo publicado también por María del Carmen Martín Rubio (1999), se afirma que el cronista español estuvo muy ligado a la panaca ${ }^{2}$ de Atahualpa a la cual pertenecía su esposa. Esto le daría una grandiosa oportunidad de conocer a fondo y de viva voz de los amautas ${ }^{3}$ y quipucamayos ${ }^{4}$ la historia del incanato.

Por otro lado, también gozaría de los favores de la empresa colonial y los gobernantes, por ejemplo, Vaca de Castro, gobernador del Perú entre 1542 y 1544 , lo escogió para interpretar sus informaciones. Andrés Hurtado de Mendoza, segundo virrey del Perú, le encargó las negociaciones con el inca rebelde Vilcabamba Sayri Tupac, y sería finalmente el primer virrey Antonio de Mendoza (1551-1552) a quien Betanzos le ofrecería la Suma y narración de los incas.

2 Las panacas eran el lugar al cual pertenecía cada gobernante inca y su familia dentro la organización políticoadministrativa del Tahuantinsuyo.

3 Amauta tenía el sentido de hombre sabio o prudente en el mundo andino.

4 Quipucamayos: encargados de leer los quipus, el cual era un sistema de cuerdas y nudos para llevar y preservar la memoria y la contabilidad sobre la población, posesión de tierras, trabajo y producción en el mundo andino. 
Para el propósito de este artículo, interesa lo que Betanzos dice sobre la fundación de la ciudad del Cuzco, considerado como centro sagrado y administrativo del Tahuantinsuyo. La Suma y narración de los incas en sus primeras páginas explica los orígenes de las tierras y gentes del Perú:

En los tiempos antiguos dicen ser la tierra e provincias de Piru oscura y que en ella no había lumbre ni día y que había en este tiempo cierta gente en ella la cual gente tenía cierto señor que la mandaba y a quien era ella sujeta del nombre de esta gente y del señor que la mandaba no se acuerdan y en estos tiempos que esta tierra era toda noche dicen que salió de una laguna que es e esta tierra del Perú en la provincia que dicen de Colla suyo un señor que llamaron Contiti Viracocha. (Betanzos, 1987, p. 11)

La cita precedente es prueba del interés de Betanzos no solo por el pasado inca, sino por todo el territorio al que él llama "provincias del Piru", una tierra que en el principio era oscura y en la cual no había luz ni día. En ese orden de ideas, Betanzos (1987) presenta el aparecimiento de una figura mítica y ordenadora del mundo, "un señor que llamaron Contiti Viracocha" (p. 11). No perdamos de vista a Viracocha, deidad que creemos que cumple un papel fundamental en la formación y ordenamiento del espacio andino y del Cuzco.

En el relato de Betanzos, Viracocha no está solo. Se apoya en otros dos viracochas para su proceso de formación del mundo andino: "e ansi partieron estos viracochas que habéis oído los cuales iban por las provincias que les había dicho el viracocha" (Betanzos, 1987, p. 13). Es con ayuda de otros viracochas que la divinidad panandina crea la gente de todas las provincias del Perú. Finalmente, el cronista cierra el proceso creativo y ordenador de los viracochas para darle paso al surgimiento del Cuzco de los incas.

[...] Y el Viracocha se pertio y vino haciendo sus gentes como ya habéis oído hasta que llegó al Cuzco donde llegado que fue dicen que hizo un señor al cual puso nombre Alcababicca y puso nombre ansi mismo a este sitio do este señor hizo Cuzco y dejando orden como después que él pasase produjese los orejones. (Betanzos, 1987, p. 15)

Como se pudo observar, para Betanzos existe un cierto orden en la historia andina: primero aparece en escena la deidad Viracocha, que organiza a modo general todas las provincias del Perú y luego el surgimiento de los orejones ${ }^{6}$ y la ciudad del Cuzco.

En el tercer capítulo de la Suma y narración de los incas aparece en pleno la gran ciudad del Cuzco y el posterior establecimiento de los incas, a quienes Betanzos les llama orejones:

5 Se conserva la ortotipografía de las fuentes consultadas y citadas en el artículo.

6 Orejones es el nombre que le da Juan de Betanzos a los incas en su crónica. 
En el lugar y sitio que hoy dicen llaman la gran ciudad del Cuzco en la provincia del Piru en los tiempos antiguos antes que en el hubiese señores orejones yngas Cuna que ellos dicen Reyes había un pueblo pequeño de hasta treinta casas pajizas y muy ruines y en ellas había hasta trinta indios y el señor y cacique deste pueblo se llamaba Alcabicca [...] Al cual pueblo llaman los moradores del desde su antigüedad Cuzco y lo que quiere decir este nombre Cozco no lo saben declarar mas de decir que ansi se nombraba antiguamente. (Betanzos, 1987, p. 17)

El Cuzco existía antes de la llegada del grupo inca. Podríamos hablar de un Cuzco pre-incaico en el cual existían otras etnias. Este dato que no es menor pues daría origen a diferentes conflictos entre las antiguas etnias y la sociedad incaica que se quería establecer en aquel lugar. Este proceso de conflicto estará arropado por versiones mitológicas en las crónicas, de lo cual hablaremos más adelante. Por ahora, continuamos con la llegada de los hermanos Ayar al Cuzco:

Y residiendo en este pueblo Alcavicca abrió la tierra una cueva siete leguas deste pueblo do llaman hoy Pocaritambo que dice casa de producimiento y esta nueva tenía la salida della cuando un hombre podría caber saliendo o entrando a gatas de la cual cueva luego que se abrió salieron cuatro hombres con sus mujeres saliendo en esta manera salió el primero que se llamó Ayarcache y su mujer con él que se llamó Mamaguaco. Y tras este salió otro que se llamó Ayaroche y tras él su mujer que se llamó Cura y tras éste salio el otro que se llamó Ayarauca y su mujer que se llamó Raguaocllo y tras estos salió otro que se llamó Ayarmango a quien después llamaron Mango que quiere decir el Rey Mango y tras éste salió su mujer que llamaron Mama Ocllo. (Betanzos, 1987, p. 17)

La versión que ofrece Betanzos sobre los hermanos Ayar y su salida de una cueva en un pueblo cercano al Cuzco llamado Pacaritambo es una de las referencias más importantes del nacimiento y fundación del Cuzco de los incas. En esta versión se destaca, además, la preeminencia e importancia de Manco Cápac, que vendría a ser el primer inca en compañía de su compañera Mama Ocllo.

Según la crónica, la travesía de los hermanos Ayar sería larga hasta asentarse en territorio cuzqueño. En un primer momento, todos se dirigirían con sus mujeres después de salir de la cueva de Pacarictambo hacia el cerro Guanacaure: "Salidos fueronse por la cordillera de los cerros siete leguas de allí hasta un cerro que esta legua y media del Cozco que llaman Guanacaure" (Betanzos, 1987, p. 18). Ayarcache vuelve a la cueva de Pacarictambo y es encerrado ahí por sus hermanos, luego estos vuelven a Guanacaure y dejan ahí en forma de huacca ${ }^{7}$ a su hermano Ayaroche. Consecutivamente pasarían a la quebrada llamada Matagua y encima de los cerros de esa quebrada:

$7 \quad$ Según el diccionario quechua de Diego Gonzáles Holguín (1608) la palabra huacca significa ydolos, figurillas de hombres y animales. Para Franklin Pease (2007) waq'a es un término que los cronistas y los evangelizadores usaron tanto para designar a los dioses "no principales" - aunque algunos lo extendieron a todas las divinidades - como para nominar los adoratorio y lugares de culto. 
[...] miraban el valle del Cuzco y el pueblo que tenía poblado Alcabicca y parecióles que era buen sitio aquel do estaba poblado aquel pueblo de Alcabicca y decendidos que fueron al sitio y ranchería que tenían entraron en su acuerdo y parecióles que sería bien poblar con los que vivían en aquel pueblo. (Betanzos, 1987, p. 19)

La crónica de Betanzos continúa su relato diciendo que Ayaroche le dice a Manco Cápac desde el cerro de Guanacaure, que fueran y tomaran posesión del valle del Cuzco al lado de los otros grupos que ya estaban allí y que llevaran consigo a su hermano Ayarauca. Manco Cápac llega al Cuzco y le manifiesta al jefe del pueblo Alcabiza que viene a quedarse ahí, porque así lo había mandado el sol:

Mango Cápac y su gente y hablaron con Alcabicca diciéndole que el sol los enviaba a que poblasen con él allí en aquel pueblo del Cuzco y el Alcabicca como le viese tan bien aderezado a él y a su compañero y las alabardas de oro que en la manos traían y el demás servicio de oro entendió que era ansi y que eran hijos del sol y dijoles que poblasen donde mejor les pareciese y el Mango agradecióselo y paresciéndole bien el sitio y asiento do agora es en esta ciudad del Cuzco.[...] El mango y su compañero con sus cuatro mujeres sembraron unas tierras de maíz la cual semilla de maíz dicen haber sacado ellos de la cueva a la cual cueva nombró este señor Mango Cápac Pacarictambo que dice casa de producimiento porque como ya habéis oído dicen que salieron de aquella cueva y su sementera hecha holgábanse y regocijábanse Mango y Alcabicca en buena amistad y contentamiento. (Betanzos, 1987, p. 20)

De esa forma se cierra el ciclo de la llegada del grupo de Manco Cápac al valle del Cuzco en el libro de Betanzos. Después de un largo proceso que va desde el nacimiento de los hermanos Ayar y su salida de la cueva de Pacarictambo, hasta llegar con la "bendición" de Ayarcache y el sol a tomar posesión de territorio cuzqueño.

Los elementos míticos destacados en el relato de Betanzos sobre Viracocha como ordenador del espacio andino y el posterior aparecimiento de los hermanos Ayar con el protagonismo de Manco Cápac son los que más nos llaman la atención. En el tercer apartado del presente artículo hacer un análisis más detallado a partir de la comparación con la otra fuente que es también objeto de estudio en este artículo: la Relación de antigüedades deste reyno del Piru.

\section{Santa Cruz Pachacuti y la Relación de antigüedades deste reyno del Piru}

La crónica de Santa Cruz Pachacuti fue compuesta, según el estudio de Carlos Araníbar (1995), un poco antes de 1630. Para Brechetti (2003) el libro habría sido redactado más exactamente hacia 1613 . Considerando esto, se podría decir que la obra vio luz en las primeras décadas del siglo XVII, por lo tanto, es posterior a la crónica de Betanzos. 
Santa Cruz Pachacuti era de origen andino. Pertenecía al grupo colla, una etnia que se encontraba bajo el dominio inca (Brechetti, 2003). Esto supone una diferencia fundamental respecto a Betanzos, porque además de tener un lugar de origen distinto, Betanzos escribe desde el ámbito cuzqueño, mientras que Santa Cruz Pachacuti escribía desde el sur andino, algo que como veremos más adelante se ve reflejado en la importancia que le da el autor indio a Tonapa, una divinidad propia de la región sur andina.

Sobre el lugar de nacimiento del cronista indio, solo se tiene información de lo que él mismo escribió en su crónica, el cual se dice originario de:

[...] Santiago de Hanan Huaigua y Hurin Huaihua Canchis de Orcosuyo entre Canas y Canchis de Collasuyo, hijo legítimo de don Diego Felipe Cóndor Canqui y de doña Maria Huairo Tari, nieto legítimo de don Baltazar Caquia Quihui y de don Francisco yamque Huanacu, cuyas mujeres mis abuelas están vivas. (Pachacuti, 1995, p. 3)

Para el historiador Carlos Araníbar no son muchos los datos que se tienen sobre la vida y trayectoria de Pachacuti. Araníbar (1995) dice al respecto que:

Un parágrafo sería suficiente si sólo fuera cosa de trazar la biografía del Yamque Juan de Santa Cruz Pachacuti Salca Maihua, cronista indio que pergeño a comienzos del siglo XVII una valiosa y muy poco divulgada historia de los Incas [...] En el restricto sentido biográfico, añadir una tilde es poner pie en el país de las adivinanzas. Pues se ignora cuándo y por qué redactó su historia, son enigma sus fechas de nacimiento y muerte, nada se sabe de su tránsito vital y no hay documento alguno de la época que lo cite por descuido. (p. XI)

A pesar de todo, el libro de Pachacuti es un rico documento sobre la historia de la población andina, la llegada del grupo de Manco Cápac al Cuzco y su posterior dominación sobre el Tahuantinsuyo. Sin embargo, al igual que pasa con otros cronistas de origen indígena, Santa Cruz Pachacuti no era ajeno al conflicto colonial de la época, pues él como sujeto indígena revive los mitos y relatos del pasado andino que le han sido transmitidos a través de la oralidad y sus ancestros en su crónica. En este proceso, intenta establecer equivalencias con algunos elementos del catolicismo colonial. Podemos observar esto cuando identifica a la divinidad Tonapa con el presunto apóstol Santo Tomás.

Santa Cruz Pachacuti también se interesa por la historia preincaica. A este periodo le va a llamar purumpacha y lo caracteriza como un momento donde

[...] todas las naciones de Tahuantinsuyo vinieron de hacia arriba de Potosí 3 o 4 ejercitos en forma de guerra. Asi vinieron poblando, tomando lugares, quedándose cada una en las compañías en los lugares baldios. A este tiempo llaman 
cállacpacha o tutayachacha. Y como cada uno cogió lugares baldios para su vivienda y moradas llaman purumpacha raccaptin a este tiempo. (Pachacuti, 1995, p. 7)

Podríamos interpretar este período como una era anterior al nacimiento y dominio incaico en el Tahuantinsuyo. Dicho periodo estaría marcado por la presencia de guerras y discordias a "falta de tierras donde habitar"8. Este aparente caos que existía tendrá un giro en la historia de Santa Cruz Pachacuti gracias a la aparición de una figura mítica, a quien consideramos parte fundamental de su obra: Tonapa. Este último va a tener una incidencia directa en el desarrollo de la historia andina que narra Santa Cruz Pachacuti, pues será el encargado de entregarle el topayauri ${ }^{9}$ al padre del primer inca Manco Cápac para la fundación del Cuzco de los incas.

Tonapa es identificado como una divinidad andina de mucha importancia que se ubica casi al nivel de Viracocha, algo sobre lo que trataremos en el tercer apartado de este escrito. Por ahora sigamos con la travesía de Tonapa:

Ha llegado a estas provincias y reinos del Tahuantinsuyo un hombre barbudo, mediano de cuerpo y con cabellos largos, con camisa larga. Dicen que era ya hombre más que pasado de mozo, que traía canas y era flaco. El cual andaba con su bordón. [...] Los indios de aquel tiempo dicen que solían burlarse diciendo: tan parlero hombre. Aunque les predicaba siempre no fue oído, porque los naturales de aquel tiempo no hicieron caudal ni caso del hombre. Pues se llamó a este varon Tonapa huiracochampa cachan, ¿no será este hombre el glorioso apóstol santo Tomás? (Pachacuti, 1995, p. 9)

Tonapa tiene un largo tránsito por el espacio andino antes de tener contacto con el padre de Manco Cápac. De dicho encuentro se desprendería una nueva historia, el nacimiento de la hegemonía inca, en cuyo proceso Tonapa tendría un papel determinante:

Este varón, [Tonapa] dicen que llego al pueblo de un cacique llamado apo Tampo, a quien estaba sujeto el pueblo. Por aquel día fue huésped el peregrino, el cual dicen que dio un palo a su bordón al apo Tampo reprendiéndolo con amor afable y el apo Tampo lo oyó con atención recibiendo el palo de su mano. De modo que en un palo recibieron lo que les predicaba, señalándoles y rayando cada capítulo de las razones. (Los viejos modernos del tiempo de mi padre Don Diego Felipe Suelen decir que casi, casi eran los mandamientos de dios. [...] Dicen que aquel palo que había dejado Tonapa entregándolo en las manos de apo Tampo se convirtió en oro fino en el nacimiento de su descendiente llamado Manco Cápac inca, cuyos hermanos y hermanas eran 7, llamados Ayar Cachi, Ayar Uchu, Ayar Auca, etc. (Pachacuti, 1995, pp. 9-15)

\footnotetext{
8 "Pasaron, muchísimos años y al cabo, después de haber estado ya poblados, había gran falta de tierras y lugares. Como no habían tierras cada día habían guerras y discordias, que todos en general se ocupaban en hacer fortalezas" (Pachacuti, 1995, p. 7).

9 Topayauri: cetro real, insignia real del inca (Araníbar, 1995, p. 397).
} 
Al igual que en la crónica de Betanzos, aparecen nuevamente en escena los hermanos Ayar, con el "liderazgo" de Manco Cápac, quien heredará de su padre el topayauri, que a su vez le fue entregado por Tonapa. Entendemos este proceso del topayauri como la representación de una insignia del poder inca que llega a manos de Manco Cápac, encargado de buscar un lugar donde asentarse junto con sus hermanos los Ayar. Como Tonapa, Manco Cápac también pasa por un largo periodo de tránsito hasta encontrar y fundar el Cuzco incaico:

De allí partió para Colcapampa con su topayauri en la mano y con una hermana que tenía, llamada Ipa mama huaco y con tra hermana y un hermano llegaron al lugar de Colcapampa. Estuvieron algunos días y de allí partieron para Huamantianca en donde estuvieron algún tiempo. De allí partieron para el lugar de Coricancha, en donde hallaron lugar apropiado para una población, en donde hallaron bueno agua de hurin chacan y hanan chacan, que son dos manantiales. Después vieron una peña que los naturales de allí -que son los alcahuizas, cullimchimas cayaocachis- llamaban cuzco caca o rumi: de ahí vino a llamarse Cuzcopampa y cuzcollacta y los incas después se intitularon Cuzco o Cuzco inca. (p. 19)

Es bastante rica la descripción que nos ofrece Santa Cruz Pachacuti (1995) de cómo fue el proceso de consolidación del Cuzco como centro sagrado y administrativo por parte de los incas. Es así como llegaría entonces la era del primer inca:

Muchas provincias y naciones de los tahuantinsuyos vinieron ellas mismas, de sus bellas gracias, con presentes ricos. La nueva del nuevo inca había corrido con gran fama dándoles en que entender. Unos estuvieron muy alegres, otros afligidos, porque oyeron que era más poderoso que ninguno de los más valientes, más venturoso en las armas y más amado que los valientes y capitanes y, en general, de los pobres y de la gente común. Y todas sus cosas iban con más prosperidad y acrecentamiento. (Pachacuti, 1995, p. 19)

Hasta aquí tratamos de abordar las obras de Juan Betanzos y Santa Cruz Pachacuti, centrándonos en sus relatos de la fundación del Cuzco. No podemos dejar de considerar los lugares desde donde escriben y hablan estos sujetos, además de la distancia temporal que separa la redacción de una y otra obra. Una de las diferencias que más sobresalen es la preponderancia de la divinidad Viracocha en la crónica de Betanzos y la de Tonapa en Santa Cruz Pachacuti. La primera, aunque puede ser considerada como una divinidad panandina, gozó de gran prestigio en el culto oficial incaico, mientras que la otra tendría su mayor auge hacia el sur andino.

También es importante señalar que el hecho de que Santa Cruz Pachacuti sea un cronista nativo, lo lleva a una tensión y confluencia entre los elementos cristianos y andinos al interior de su relato, como sucede en la relación que establece entre Tonapa y el supuesto apóstol Santo Tomas, tensiones que aparecen en un grado menor en el escrito de Betanzos. Sin embargo, eso no nos impide 
hacer este tipo de comparaciones, ya que hemos podido apreciar que ambos prestan bastante atención hacia el pasado indígena, sus orígenes y la posterior consolidación con centro en Cuzco de los incas.

\section{El Cuzco desde las obras de Betanzos y Pachacuti: análisis a partir del concepto memoria}

El Cuzco, sin duda alguna, es parte fundamental en las crónicas coloniales del siglo XVI y XVII que se preocuparon por entender la historia y cosmología andina ${ }^{10}$. Lo expuesto en la primera parte del artículo respalda esta información. Por este motivo, muchos historiadores se han dado a la tarea de explicar cómo surge el Cuzco como centro del poder incaico.

Para María Rostworowski (1999), en la zona del Cuzco existían varias etnias que ocupaban la región antes de la llegada de los grupos de Manco Cápac, entre ellos los ayarmacas ${ }^{11}$. Luis Millones (1987) dice que con los pequeños fragmentos de información que se tienen, se podría indicar que hacia $1200 \mathrm{~d}$. C. el valle del Cuzco estaba dividido en un conjunto de curacazgos en rivalidad continua, sin que ninguno llegara a dominar la región. Millones (1987) agrega que los incas llegados más tarde, no eran distintos de los Sañu, Alcaviza o Ayarmaca, que se tienen por originarios.

De acuerdo a lo planteado por estos autores, basados en estudios documentales y arqueológicos, existe un cierto consenso en cuanto al proceso de ocupación del grupo inca en el Cuzco. Esto lo pudimos encontrar en las crónicas de Betanzos y Pachacuti. Dichas versiones tienen un sustento arqueológico y a la vez son arropadas dentro de la mitología y la tradición oral andina como expresa Rostworowski (1999):

Esta versión andina, de la ocupación del lugar del Cusco primitivo por grupos que llegaron y se establecieron muchos antes del arribo de los de Manco Cápac, está de acuerdo con los datos arqueológicos. En la cerámica del intermedio tardío del Cusco se nota el reemplazo de una cultura por otra. Este fenómeno demuestra que la cultura inca tiene raíces más importantes en las tradiciones de Ayacucho, Nasca y Tihuanaco, y no en las culturas más antiguas del valle. (p. 35)

Además de narrar los eventos sobre Manco Cápac y los hermanos Ayar y su ocupación del Cuzco, en los escritos de Santa Cruz Pachacuti y Betanzos también aparecen dos divinidades propiamente andinas: Viracocha y Tonapa.

10 Sobre la importancia del Cuzco en las crónicas coloniales, son relevantes los trabajos de Franklin Pease donde se hace mención de las Crónicas cuzqueñas (Pease, 1995; 2010).

11 "En la zona de Cusco, las etnias que ocuparon la región antes de la llegada de los grupos de Manco, y los propios comienzos de los incas corresponde al intermedio tardío o a los desarrollos tardíos. Killke es el nombre de una cerámica de baja calidad artística que predominó durante dicha época, y a manera de hipótesis la identificamos como perteneciente a los grupos ayarmancas, cuyos jefes étnicos tenían por nombres genéricos Tocay Cápac y Pinahua" (Rostworowski, 2007, p. 27). 
María Rostworowski (2007) dice que Viracocha sería el más conspicuo de los dioses del ámbito andino. Es posible que su difusión se debiera a los religiosos católicos que buscaban un nombre para explicar a los naturales el concepto de Dios. Para Franklin Pease (2007), dioses similares a Viracocha -o Wiracocha- existían en otras partes de los Andes y su actividad relaciona la tierra con el cielo. Para Pease es posible que muchos de estos dioses - como Cuniraya, Pachacama, Tunapa, etc. - sean en realidad denominaciones locales de una noción de divinidad similar a Viracocha. Finalmente, Luis Millones (1987) sostiene que Viracocha, al igual que la divinidad solar inca, en diferentes grados y a través de la historia, habría perdido sus raíces comunales y regionales, y en el momento de la conquista compartían con los incas el poder formalizado que los consagraba como dioses del "panteón" oficial del Tahuantinsuyo.

Para los cronistas del siglo XVI y XVII, Viracocha tendrá un papel muy importante. Será colocado como el creador, ordenador del mundo y de los habitantes del espacio andino. Este rol que juega Viracocha en las crónicas también puede explicar, según lo comentado por María Rivara (2000), su prestigio como máxima divinidad del mundo prehispánico, gracias a que los cronistas hombres occidentales del siglo XVI- lo elevaron a esa posición buscando una analogía con el dios creador del catolicismo ${ }^{12}$.

Betanzos no sería ajeno a esa analogía que los cronistas llegados del mundo católico-occidental hacían entre sus conocimientos religiosos, su bagaje cultural y lo que se encontraban en el "Nuevo Mundo". Como pudimos observar, para Betanzos los primeros habitantes, el orden y la forma de las cosas del Tahuantinsuyo tenían origen en el mito de Viracocha y su función de dios "hacedor".

Sobre Tonapa - quien es mencionado y aparece como una figura de bastante relevancia en el relato de Pachacuti-, Rostworowski (2007) dice que entre los dioses del sur andino, parece haber sido una divinidad muy antigua, cuya área de influencia llegó a su máxima extensión antes del auge del culto a Viracocha. Por otra parte, Franklin Pease (2007) cree que Tonapa pudo haber sido una denominación local para una divinidad similar a Viracocha. ¿Pero por qué Santa Cruz Pachacuti representa a Tonapa como el apóstol Santo Tomás? Un caso similar se encuentra en Guaman Poma de Ayala, que aunque no identifique una divinidad con algún apóstol en específico, considera que

12 “Wiracocha es así comúnmente considerado como la entidad de máxima jerarquía en el mundo religioso prehispánico, debido justamente a que el cronista, hombre perteneciente al mundo y la cultura occidental del siglo XVI, al convertirlo al signo cristiano, le está otorgando su mayor sentido interpretativo. El hecho de que Viracocha haya sido identificado con el dios de los cristianos, explica a su vez la continuidad en su ubicación como máxima entidad religiosa" (Rivara, 2000, p. 100). 
uno de estos pasó por los Andes: el famoso apóstol San Bartolomé13. Esta idea tuvo fuerza en los cronistas indígenas debido a que era necesario buscar un puente entre la religión católica y el pasado andino prehispánico. Sobre la forma humanizada que adquiere Tonapa en la obra de Santa Cruz Pachacuti, Millones (2008) dice que se daba con frecuencia el interés de cierta corriente de cronistas e historiadores del XVI y XVII de entremezclar el panteón precolombino con la figura de los predicadores que habrían llegado milagrosamente al "Nuevo Mundo". El autor agrega que estos acontecimientos demostrarían la capacidad de los indígenas para acercarse al mensaje cristiano. Además, en el catolicismo de la época, se pensaba que el mensaje de Cristo había llegado a todos los confines de la tierra, en algunos casos a través de los apóstoles.

Fue necesario hacer este análisis para identificar dos deidades que nos parecen de vital importancia en las crónicas, y que están vinculadas directa o indirectamente con la formación del Cuzco incaico por medio de la gesta fundacional de Manco Cápac. Viracocha, desde la perspectiva de Betanzos, sería el origen de todo. Por esta razón, también sería el origen del posterior surgimiento de Manco Cápac y sus hermanos para fundar el poderío inca con centro en Cuzco. Por otro lado, para Santa Cruz Pachacuti, Tonapa es el que guía aquel proceso, pues es él quien a través del símbolo del topayauri o insignia real del inca, le hace llegar a Manco Cápac la misión de buscar un lugar donde posicionarse junto con sus hermanos: ese lugar sería el Cuzco.

Pero, ¿cómo tuvieron acceso estos cronistas a la información que plasmaron en sus crónicas? Tanto Betanzos como Pachacuti reivindican que lo escrito por ellos en sus crónicas, parte de informaciones que escucharon y recolectaron entre los "naturales" y relatos de "viva voz". Betanzos (1987) lo dice en su carta al virrey Mendoza donde explica las condiciones en las cuales fue terminada su Suma y narración:

[...] Lo cual yo para presente y servicio que yo a vuestra Excelencia hiciese en mi falta y la historia de semejante materia no da lugar pues para ser verdadero y fiel traducidor tengo de guardar la manera y orden del hablar de estos naturales y viniendo al propósito digo que en esta presente escritura algunos ratos empleara vuestra Excelencia los ojos para leerla la cual aunque no sea volumen muy alto ha sido muy trabajoso lo uno porque no la traduje y recopié [sic] siendo informado de uno sólo sino de muchos y de los más antiguos y de crédito que hallé entre estos naturales. (p. 7)

Que los relatos fueron recogidos "de muchos y de los más antiguos naturales", o que fueron testigos vivientes y oyentes de lo que escriben, es una

13 "Cuando fue de edad de ochenta años desde que nació Sinche Roca Inga, nació nuestro señor y salvador Jesucristo, y en su vida subió a los cielos y bajó el Espíritu Santo en los apóstoles, y así se repartió por el mundo los apóstoles, y así le cupo al apóstol San Bartolomé estas Indias de este reino del Perú, y así vino a este reino el dicho apóstol" (Poma de Ayala, 2005, p. 72). 
afirmación constante en los cronistas del XVI y XVII. En el caso de Juan de Betanzos nos podríamos arriesgar a decir que por el contenido de su obra y las condiciones en que la hizo, su afirmación de que consultó, entrevistó y escuchó de los más antiguos para recoger las informaciones y redactar la Suma y narración de los incas no estaría muy alejada de la realidad.

El caso de Santa Cruz Pachacuti es bastante similar, teniendo en cuenta que a diferencia de Betanzos, él formaba parte de la historia y cultura andina de la que hablaría en la Relación de antigüedades deste reyno del Piru relatos a los cuales tuvo acceso desde su niñez:

Digo que hemos oído, siendo niño, noticias antiquísimas y las historias, barbarisimos y fábulas del tiempo de las gentilidades, que son como gente se sigue (que, entre los naturales, las cosas de los tiempos pasados siempre las suelen parlar. (Pachacuti, 1995, p. 7)

Las historias y relatos a los que se refiere Santa Cruz Pachacuti deben ser producto de una larga tradición oral andina, que él ha recibido y colocado en el código escrito europeo. Ahora bien, estos relatos orales que suponemos fueron de los que se valieron los cronistas en cuestión para hacer sus escritos, deben estar encuadrados dentro de una memoria que le daría consistencia y coherencia a esas historias que hemos analizado en las obras de Betanzos y Santa Cruz Pachacuti.

Los diversos relatos orales que consultaron los cronistas pueden pensarse como múltiples memorias individuales, que a la vez componen una gran memoria colectiva que identifica y da cohesión a un determinado grupo asociado a un pasado común.

Sobre esto último, Maurice Halbwachs (2004) propone algunos elementos interesantes. Dicho autor hace la distinción entre dos tipos de memoria; una colectiva y otra individual:

Por lo tanto, habría memorias individuales y, por decirlo de algún modo, memorias colectivas. Dicho en otras palabras, el individuo participaría en dos tipos de memorias. [...] La memoria colectiva, por otra parte, envuelve las memorias individuales, pero no se confunde con ellas. (pp. 53-54)

La memoria colectiva estaría conformada por las diversas memorias individuales de un determinado grupo social. Esta serviría a la vez como un marco de referencia social para la construcción de la memoria de cada sujeto. Ahora, lo que consideramos más importante del estudio sobre memoria hecho por Halbwachs es lo que dice respecto a los marcos sociales de la memoria. Estos serían los encargados de situar la memoria en un determinado espacio-tiempo. Estos marcos sociales de la memoria cumplirían la función de agrupar los 
recuerdos y experiencias individuales de los grupos sociales, sea la familia o una nación.

Entendemos que los diferentes relatos y memorias individuales que "rescataron" y escucharon nuestros cronistas, están inscritos dentro de una memoria colectiva andina más amplia, que responden a un pasado común y dioses comunes. La memoria colectiva también respondería a una conexión con lugares físicos o marcos espaciales como expone Halbwachs (2004):

Pero el lugar ha recibido la huella del grupo y a la inversa. Entonces todo lo que hace el grupo puede traducirse en términos espaciales. Cada aspecto, cada detalle de este lugar tiene un sentido que solo pueden comprender los miembros del grupo. (pp. 133-134)

Es bastante útil la idea de Halbwachs sobre un marco espacial de la memoria, si tenemos en cuenta que lo relatado por nuestros cronistas refleja cómo la ciudad del Cuzco — gracias a su importancia social, política y sagrada dentro del Tahuantinsuyo- es un espacio ligado a la memoria andina, en la cual actuaron dioses y héroes culturales que, para bien o para mal, fundaron el Cuzco junto con el gobierno de los incas.

Por otra parte, el trabajo de Aleida Assmann (2011) propone el concepto, memoria cultural. Sobre este trabajo nos parecen importantes las conceptualizaciones que hace la autora sobre dos formas de memoria, una cultural y otra comunicativa:

Hay, entonces, un paralelo entre la memoria cultural, que supera épocas y es guardada en textos normativos, y la memoria comunicativa, que normalmente liga tres generaciones consecutivas y se basa en los recuerdos transmitidos oralmente. (p. 17) $)^{14}$

Creemos que es posible estudiar las crónicas coloniales a partir de los conceptos de memoria cultural y comunicativa propuestos por Assmann, pues suponemos que en el contenido de dichas crónicas -en especial las que fueron hechas a través de entrevistas orales-, existe una memoria comunicativa que fue legada oralmente entre generaciones hasta la llegada de los colonizadores, y una memoria cultural que, nos arriesgamos a decir, estuvo representada por la empresa colonial para registrar en las crónicas el pasado andino prehispánico:

En cuanto los procesos de recordación, ocurren espontáneamente en el individuo y siguen reglas generales de los mecanismos psíquicos, en el nivel colectivo e institucional esos procesos son guiados por una política específica de recordación y olvido. Ya que no hay auto-organización de la memoria cultural, ella depende de medios y políticas, y el salto entre la memoria individual y viva para la memoria cultural y artificial y ciertamente problemático, pues trae consigo el riesgo de la deformación, de la reducción y de la instrumentalización de la recordación. (Assman, 2011, p. 19)

14 Los trechos citados de la obra de Aleida Assman (2011) serán traducidos del portugués al español. 
Creemos que es viable pensar en una memoria cultural representada por la Corona y la iglesia en el virreinato del Perú. Estas instituciones, en su afán de poder conocer para dominar, se vieron en la tarea de investigar y registrar por medio de la escritura la vida de los diferentes grupos indígenas de América. Un ejemplo de este tipo de memoria cultural podrían ser los diversos cronistas españoles como Juan Betanzos y el caso de cronistas indígenas como Santa Cruz Pachacuti, quienes también tuvieron que valerse de la escritura española para registrar la vida y costumbres de sus antepasados, muchas veces también como una forma de resistencia y reclamo al sistema colonial.

Por otra parte, las crónicas, además de realizar ese esfuerzo de ir atrás en la memoria de los pueblos indígenas, encontraron un problema: llevar al papel la memoria de unas sociedades que eran predominantemente orales. Para intentar abordar la problemática de una "transcripción" de la oralidad en el caso del estudio cronístico virreinal, tenemos que volver al tema de la memoria de los pueblos que se valen de la oralidad para explicar su pasado y darle cierta cohesión a su sociedad. Jacques Le Goff en el Orden de la memoria (1991), intenta explicar cómo opera la memoria en sociedades orales. En este sentido, afirma: "La esfera principal en la que se cristaliza la memoria colectiva de los pueblos sin escritura es la que da un fundamento - aparentemente históricoa la existencia de etnias o de familias, es decir a los mitos de origen" (p. 136).

Por lo tanto, los cronistas — sean de origen indígena o europeo-recibieron lo que podemos considerar como tradiciones mitológicas por parte de las sociedades indígenas. Estas narrativas debieron haber pasado por un proceso de filtro y selección de acuerdo a lo que a los propios cronistas les interesaba mostrar y escribir en sus documentos. Es necesario destacar que este proceso se vuelve aún más problemático si entendemos el paso de la oralidad a la escritura como una subordinación de la primera bajo la segunda.

Este último proceso que hemos comentado lo problematiza Martín Lienhard (1990):

En resumidas cuentas, la operación escritural en América del 11/10/1492, la primera que se realiza en América a partir del alfabeto se puede considerar como el grado cero de la escritura —al estilo occidental — en el continente; un grado cero que carga, sin embargo, con todo el peso de su pasado europeo: la vinculación de los poderes político y espiritual. (p. 33)

Lienhard va a calificar este proceso de la imposición de la escritura occidental en América como un "fetichismo de la escritura", que se manifestará en el papel y que tendrá una función político-religiosa en pro de la posesión y evangelización del territorio y población americana. Este proceso se da de forma natural en cronistas como Betanzos, que traen consigo toda la tradición 
de la escritura occidental. Pero, ¿qué pasa en el caso de cronistas como Santa Cruz Pachacuti? Esta interrogante también se la platea Lienhard (1990):

En los no muy numerosos autores indígenas que surgen en los decenios consecutivos al primer contacto, se nota el impacto de ese núcleo ideológico: confiados en el poder del discurso escrito, unos indios nobles como el apenas mencionado Titu Cusi, Guaman Poma o los dignatarios mesoamericanos autores de títulos genealógicos y de cartas reivindicativas, parecen atribuir al mensaje escrito una eficacia intrínseca, independiente del aparato político que la sustenta. (p. 36)

En suma, tanto Betanzos como Pachacuti tuvieron acceso a la memoria colectiva de ciertos grupos, que les transmitieron oralmente los mitos que correspondían al inicio del Tahuantinsuyo, la fundación del Cuzco, el comienzo de la hegemonía inca, las travesías de dioses como Viracocha o Tonapa, y "héroes o heroínas culturales/fundacionales" como Manco Cápac o Mama Ocllo. Ambos cronistas también pasaron por el proceso de llevar la oralidad a la escritura hispánica. Seguramente para los dos fue un proceso bastante complejo, pues si bien Betanzos venía ya relacionado al poder de la escritura, tuvo que intentar traducir a sus propios conocimientos todo lo que le contaban los andinos sobre sus cosmologías. Por otro lado, Pachacuti, aunque estaba bastante familiarizado con la oralidad y las cosmologías andinas, tuvo que apropiarse y buscar un puente entre sus conocimientos ancestrales y los nuevos códigos que le eran impuestos desde la empresa colonial.

\section{Conclusiones}

Este trabajo buscó reflexionar sobre cómo fue el proceso de fundación de la ciudad del Cuzco y su ocupación por parte de los incas en las crónicas coloniales de Juan de Betanzos (1551) y Santa Cruz Pachacuti (1613). Escogimos estos cronistas porque, como vimos a lo largo del trabajo, estuvieron interesados por el pasado prehispánico.

Los documentos trabajados solo fueron un pequeño ejemplo de cómo el Cuzco, la dominación y expansión incaica son parte fundamental dentro de la narrativa de las crónicas coloniales del XVI y XVII, así como también lo es la participación de divinidades de gran prestigio dentro del "panteón" andino, y de héroes fundacionales como Manco Cápac. Creemos que es a partir del análisis de un hecho concreto dentro de las crónicas coloniales — como la fundación del Cuzco de los incas-, que se pueden comenzar a buscar las variaciones y semejanzas entre los diversos cronistas que se interesaron por estas temáticas en el periodo colonial temprano.

Este tipo de comparaciones entre documentos, que a pesar de estar enmarcados dentro del periodo colonial peruano y que son heterogéneos entre sí, nos permiten pensar en los usos, representaciones y transformaciones que hace la 
escritura virreinal sobre los aspectos del mundo andino a lo largo del tiempo, un ejemplo de ello es el probable uso político que se hace de un momento central en la historia andina como la fundación del Cuzco de los incas. Es posible afirmar que el protagonismo de una figura como Viracocha en los documentos, puede ser síntoma de la influencia del Cuzco en ellos y, más aún, en sujetos que políticamente tuvieron una relación tan cercana a la élite inca como Juan de Betanzos. Por otro lado, están las variaciones y rupturas que pueden existir en escritos como los de Santa Cruz Pachacuti, donde el papel central lo ocupan otras deidades más representativas de su lugar de origen como Tonapa. Esto último podría ser más explorado en los documentos como los de Felipe Guaman Poma de Ayala o el manuscrito de Huarochiri, donde existen ciertas discrepancias y diferencias en relación con las narrativas cuzqueñas. Como se dijo anteriormente, esto abre el camino para reflexiones sobre los usos y apropiaciones del pasado andino que hacen los diversos actores de la época colonial temprana, cuyos usos estarán directamente relacionados al contexto y objetivos que quisieran alcanzar y distinguir los cronistas.

Por último, es importante resaltar que también se buscó traer a discusión una nueva herramienta teórico-metodológica para el análisis de la escritura virreinal que ya goza de grandes debates al interior del campo historiográfico, esto es, el concepto de memoria y el concepto memoria cultural planteado por Aleida Assman. Nuestra apuesta por el diálogo de estos conceptos a través de los estudios del Perú antiguo que hemos realizado, tiene que ver con que ellos permiten comprender y detallar el tránsito de la oralidad andina recibida por los cronistas y sus diversas transformaciones hasta llegar a la escritura alfabética. En este sentido, es probable comenzar a pensar no solo en el filtro español de la época para la construcción de los relatos, sino en las diversas voces nativas que aparecen en esa serie de narrativas.

\section{Agradecimientos}

Este artículo de reflexión nace de una trayectoria de investigación que vengo desarrollando desde mi formación de pregrado en Historia y la Maestría Interdisciplinar en Estudios Latinoamericanos en la Universidad de la Integración Latinoamericana (Unila, Brasil).

\section{Referencias}

Araníbar, C. (1995). Relación de antigüedades de este reino del Perú. Lima: Fondo de Cultura Económica.

Assmann, A. (2011). Espaços da recordação; formas e transformações da memória cultural. São Paulo: Editora da Unicamp.

Betanzos, J. (1987). Suma y narración de los incas. Madrid: Atlas. 
Brechetti, A. (2003). "... Los pintaré como estaban puestos: hasta que entró este reyno el santo ebangeleo", Santa Cruz Pachacuti Yamqui, 1613. Anales del museo de América, 11, 81-102. Recuperado de https://dialnet.unirioja.es/servlet/articulo?codigo $=961567$

De la Espada, J. M. (1880). Suma y narración de los incas: que los indios llamaron capaccuna que fueron señores de la ciudad del Cuzco. Madrid: Archivo histórico nacional.

Fossa, L. (2006). Narrativas problemáticas: Los inkas bajo la pluma española. Lima: Instituto de estudios peruanos.

Halbwachs, M. (2004). La memoria colectiva. Zaragoza: Prensas de la Universidad de Zaragoza.

Le Goff, J. (1991). El orden de la memoria: el tiempo como imaginario. Barcelona: Paidós.

Lienhard, M. (1990). La voz y su huella: Escritura y conflicto étnico social en América Latina (1492-1988). La Habana: Casa de las Américas.

Martín, R. M. (1987). Juan de Betanzos (1551) Suma y narración de los incas: prólogo de María del Carmen Martín Rubio. Madrid: Atlas.

Martín, R. M. (1999). Juan de Betanzos: el gran cronista del imperio inca. Anales del museo de America, 7, 111-124. Recuperado de: https://dialnet.unirioja.es/servlet/articulo?codigo=1455901

Millones, L. (1987). Historia y poder en los Andes centrales (desde los orígenes al siglo XVII). Madrid: Alianza Editorial.

Millones, L. (2008). Dioses y demonios en los andes. En A. López, y L. Millones (Ed.), Dioses del norte, Dioses del sur: Religiones y cosmovisión en Mesoamérica y los Andes (pp. 145- 271). Lima: IEP.

Pachacuti, Y., J. (1995). Relación de antigüedades de este reino del Perú. Lima: FCE.

Pease, F. (1995). Las crónicas y los Andes. Lima: Fondo Editorial Pontificia Universidad Católica del Perú.

Pease, F. (2007). Los Incas. Lima: Fondo Editorial Pontificia Universidad Católica del Perú.

Pease, F. (2010). El dios creador andino. Cuzco: Colección Qillqa Mayu.

Poma de A, F. (2005). Nueva corónica y buen gobierno. México: Fondo de Cultura Económica.

Rivara de T, M. (2000). Pensamiento prehispánico y filosofía colonial en el Perú. Lima: FCE.

Rostworowski, M. (1999). Historia del Tahuantinsuyo. Lima: IEP.

Rostworowski, M. (2007). Estructuras andinas del poder: Ideología religiosa y política. Lima: IEP. 